The impact of Organizational silence on Job Burnout Applied study ...

Dr. Ehab Lotfy AbdElaal Abied \& Dr. Hassan Mahmoud Aly Khalil

\title{
The impact of Organizational silence on Job Burnout Applied study on doctors and nursing staff at Ain Shams University Hospitals
}

\author{
Dr. Ehab Lotfy AbdElaal Abied \\ Imam Abdulrahman Bin Faisal University, KSA \\ Dr. Hassan Mahmoud Aly Khalil \\ $\mathrm{PhD}$ in Business Administration
}

\section{Introduction of the study}

Morrison and Milliken 2000 showed that organizational silence leads to dissonance, which in turn reduces motivation, satisfaction and commitment within the organization. Other evidence suggests that organizational silence leads to stress, denial, dissatisfaction, and disconnection among staff. In addition, organizational silence makes staff feel that they do not control their work (Nikolaou, Vakola et al. 2011) (Baran and Giderler 2017).

Job burnout today attracts considerable attention from researchers and organizational leaders and is primarily related to important organizational and individual outcomes such as functional performance, organizational behavior, functional behavior and negative psychological consequences (Tahmasebi, Sobhanipour et al. 2013) (Maruyama, Suzuki et al. 2016).

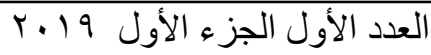

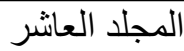


The impact of Organizational silence on Job Burnout Applied study ...

Dr. Ehab Lotfy AbdElaal Abied \& Dr. Hassan Mahmoud Aly Khalil

The challenges faced by doctors and nursing staff in hospitals are: high workload, irregular working hours, the need to empathize with people in distress, accountability in the face of ambiguity, conflicts within the team, the role of uncertainty and the race against time are the daily challenges they face (Bagheri, Zarei et al. 2012) (Tangirala and Ramanujam 2008) (Maruyama, Suzuki et al. 2016).

In light of the above, the current study aims at clarifying the effect of organizational silence on job burnout among both doctors and nursing staff at Ain Shams University hospitals; and providing relevant solutions to change the level of organizational silence in order to reduce job burnout.

\section{Theoretical Framework:}

The theoretical framework of the research is divided into two main sections, where the researcher in the first section deals with organizational silence while the second part deals with the subject of job burnout, as follows:

\subsection{Organizational Silence:}

Johannesen, 1974 was the first to refer to the definition of silence at the organizational level, where he pointed out that it means not sharing information between workers and each other (Baran and Giderler 2017). Intensive academic attention to the concept of organizational silence began in the organizational behavior literature based on two basic studies in this field, where

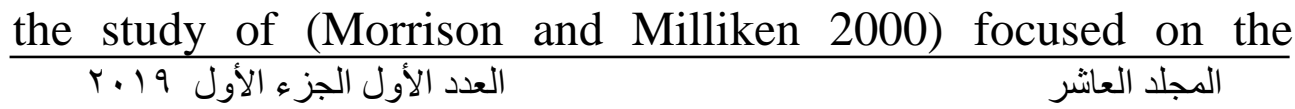


The impact of Organizational silence on Job Burnout Applied study ...

Dr. Ehab Lotfy AbdElaal Abied \& Dr. Hassan Mahmoud Aly Khalil

determinants and outcomes of organizational silence and defined it as a prevalent behavior of workers' refusal to reveal their opinions, ideas and suggestions about potential work problems. (Pinder and Harlos 2001), developed a concept of silence as a reaction to unfair regulatory practices, and as an adverse concept to the concept of expression which means not to express any of the true expressions of an individual's emotional, cognitive, and behavioral evaluations of organizational circumstances.

(Beheshtifar, Borhani et al. 2012) notes that organizational silence is a negative phenomenon due to the reluctance of workers to express their opinions and ideas on labor issues, both technical and organizational opinions, which negatively affects the processes of improvement and organizational development. (Kostiuk 2012) explained that the organizational silence includes those regulatory positions in which information is hidden from sender to receiver and thus it is equivalent to secrets. (Bagheri, Zarei et al. 2012) defined it as a phenomenon in which employees deliberately do not express their views, ideas and information about the organization's environment.

As for the factors that cause organizational silence, there are many factors, such as the influence of colleagues on organizational silence by not supporting each other. Because when the employees do not trust each other, they will choose silence (Çakı1 12008), Some management beliefs and procedures, such as the management's belief that the staff don't like the effort 
The impact of Organizational silence on Job Burnout Applied study ...

Dr. Ehab Lotfy AbdElaal Abied \& Dr. Hassan Mahmoud Aly Khalil

and cannot be trusted when making decisions that serve the interests of the organization, as well as the belief that the management better identifies the issues of the organization, is also considered a major cause of silence (Kopelman, Prottas et al. 2008).While (Sayğan 2011) suggests that organizational silence may be due to the characteristics of the organization, such as its structures and culture.

A number of researchers and writers have dealt with the phenomenon of organizational silence in three main dimensions, based on the behavior of workers within the organization, namely the Acquiescent Silence, Defensive Silence and Prosocial Silence. The researcher presents these dimensions as follows:

- Acquiescent Silence : And it means blocking information and opinions as a desire to retire or surrender. The employee follows this behavior based on his belief that the expression is useless and that speaking about or reporting problems is unlikely to make a difference (Dyne, Ang et al. 2003).

- Defensive Silence: And here the purpose of silence is to protect oneself against any external threats. This type involves the withholding of information because of the fear that the expression of opinions and ideas may result in personal risks. This self-defense motive may be because of the fear of being blamed for the problem (Baran and Giderler 2017).

العدد الأول الجزء الأول 9 1.r

المجلد العاشر 
The impact of Organizational silence on Job Burnout Applied study ...

Dr. Ehab Lotfy AbdElaal Abied \& Dr. Hassan Mahmoud Aly Khalil

- Prosocial Silence: The purpose of silence is to maintain the individual's relations with others. In other words, the reason for silence is to prevent or block any information or ideas taking into consideration the feelings of others. This type of silence is based on a great deal of cooperation and altruism shown by the employee to others (Beheshtifar, Borhani et al. 2012).

\subsection{Job Burnout:}

The early beginnings of the term Burnout were back to the scientist Freudenberger during his study of the response to pressure on workers in the service sector, he called it "a state of emotional, physical exhaustion due to stress in addition to inability to meet the requirements of the profession " (Schaufeli, Leiter et al. 2009).

(Carolina 2010) defined the job burnout as a state of physical and emotional fatigue caused by inappropriate working conditions. (Lambert, Hogan et al. 2012) defined it as the discontent, anxiety and psychological pain that result from boredom at work and lead to a person's emotional and physical exhaustion.

A number of researchers and writers have dealt with the phenomenon of Job burnout in three main dimensions, based on the behaviors of workers within the organization, namely: Emotional Exhaustion, Depersonalization and Reduced

العدد الأول الجزء الأول 19. المجلد العانشر 
The impact of Organizational silence on Job Burnout Applied study ...

Dr. Ehab Lotfy AbdElaal Abied \& Dr. Hassan Mahmoud Aly Khalil

Professional Accomplishment. The researcher presents these dimensions as follows:

- Emotional Exhaustion:It is a feeling of continuous emotional depletion in the workplace, and this dimension is considered one of the most important dimensions of burnout, as it represents the main stone in the construction of burnout (França, Ferrari et al. 2012).

- Depersonalization: And it refers to the abstraction of human characteristics, which include the continuous sense of lacking idealism, where the individual resort to rough dealing with colleagues, which profoundly affects the form of dealing with each other, Despite the divergent views of researchers about the name, they agreed that it represented pessimism, harshness in dealing with others, coldness, and frequent criticism (Maruyama, Suzuki et al. 2016).

- Reduced Professional Accomplishment: Refers to an individual's sense of inadequacy, failure to obtain achievements commensurate with his own aspirations, low motivation, poor productivity, and failure in work (Day, Sibley et al. 2009).

\section{Literature Review}

The researcher reviewed the studies that dealt with the topics of organizational silence, job burnout, and studies that linked between them, as follows:

العدد الأول الجزء الأول 19 •

المجلد العاشر 
The impact of Organizational silence on Job Burnout Applied study ...

Dr. Ehab Lotfy AbdElaal Abied \& Dr. Hassan Mahmoud Aly Khalil

\subsection{Literature of the Organizational Silence:}

(Tangirala and Ramanujam 2008) study examined the relationship between organizational variables and organizational silence on a sample of US hospital nurses of 606 individuals, the most important results of the study showed that there is an inverse relationship between organizational silence and organizational commitment and procedural justice, while there is a positive relationship between the organizational silence and the strength and position of the supervisor. While the study (Brinsfield 2009) aimed to develop a model that illustrates the factors affecting the silence of workers, and the study found the existence of an inverse relationship between the Defensive Silence and both procedural justice and the degree of trust for the administration and direct supervisor. There is an inverse relationship between the Acquiescent Silence and Job Satisfaction, while there is a positive relationship between Acquiescent Silence and Psychological withdrawal.

(Bagheri, Zarei et al. 2012) identified the factors that cause organizational silence which are: the characteristics of the senior management team, environmental and organizational characteristics, organizational structure and policies, and management's fear of negative feedback and demographic differences. The study showed the negative effects of organizational silence which are: low job satisfaction, low level $\frac{\text { of efficiency and performance, psychological stress, high }}{\text { العدلد الأول الجزء الأول } 9.4}$ 
The impact of Organizational silence on Job Burnout Applied study ...

Dr. Ehab Lotfy AbdElaal Abied \& Dr. Hassan Mahmoud Aly Khalil

turnover and low communication with the internal environment of the organization. While (Panahi, Veiseh et al. 2012) focused on the analysis of factors affecting organizational silence and their relation to the organizational commitment. The study concluded that there is a relationship between the dimensions of organizational silence and organizational commitment. There is also a positive relationship between the attitudes of upper management and direct supervisors towards silence and between staff silence. There is an inverse relationship between the availability of communication opportunities and organizational silence. In the same context, (Deniz, Noyan et al. 2013) study, which was applied to a sample of 175 private hospital staff in Istanbul, found a negative correlation between Defensive Silence and organizational commitment, while the study did not substantiate the relationship between the other dimensions of the silence of employees and the organizational commitment.

The study (Elçi, Erdilek et al. 2014) focused on the nature of the relationship between the organizational silence and the workers' attitudes towards leaving work. The study found that there is a positive effect for organizational silence in the intention to leave work.

The study (Çınar, Karcıoğlu et al. 2013) aimed at understanding the relationship between organizational silence and organizational citizenship behavior. The study found a strong

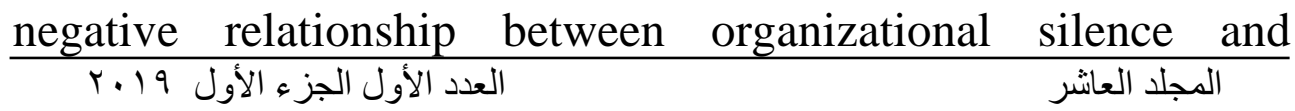


The impact of Organizational silence on Job Burnout Applied study ...

Dr. Ehab Lotfy AbdElaal Abied \& Dr. Hassan Mahmoud Aly Khalil organizational citizenship. In the same context, (Acaray and Akturan 2015) study found no significant effect for the dimensions of organizational silence on the dimensions of organizational citizenship behaviors. And that Defensive Silence has a negative impact on the dimensions of organizational citizenship behaviors. The Prosocial Silence has a positive impact on the dimensions of organizational citizenship behaviors.

\subsection{Literature of the Job Burnout:}

Many researchers dealt with the phenomenon of job burnout and its relation to many other organizational variables. (Schaufeli, Leiter et al. 2009) examined the relationship between the requirements of the job resources, the dedication to work and the job burnout. The study concluded that job burnout is influenced by the increase of requirements and workloads, which result in many health problems experienced by the individual.

The study (Day, Sibley et al. 2009) found a significant positive effect for the pressures and hazards of the work environment on the level of job burnout among workers, and that there is a negative effect for the degree of job control on the job burnout.

The study of (Adriaenssens, De Gucht et al. 2015), by reviewing the applied studies in the field of job burnout for emergency patients during the period 1989 to 2014, found that $26 \%$ of emergency patients suffer from job burnout, it was also found that work-related factors, including job characteristics, 
The impact of Organizational silence on Job Burnout Applied study ...

Dr. Ehab Lotfy AbdElaal Abied \& Dr. Hassan Mahmoud Aly Khalil organizational factors, and exposure to disturbing events, were identified as key determinants of job burnout in this category of workers. The study of (Cañadas-De la Fuente, Vargas et al. 2015) supported the high level of job burnout among nursing staff at public health centers in Andalusia, Spain. The determinants of the job burnout are imbalance, acceptance, social openness, and conscience alertness.

(Qureshi, Rawlani et al. 2015) found that 29.5\% of plastic surgeons in the United States suffer from high level of job burnout, and that: working hours, evening phone calls, medical errors and workplace, as well as lack of quality of work life, low professional satisfaction, and the conflict of family role and work role are the most important factors affecting the job burnout for these doctors.

(Maruyama, Suzuki et al. 2016) noted that the factors affecting the job burnout of 1644 female nurses in Japanese hospitals were: duration of experience, overtime, ability to selfassertion, and avoidance of punishment. (Majerníková and Obročníková 2017) study found a significant negative correlation between self-esteem, sense of cohesion, and job burnout.

\subsection{Literature of the organizational silence and Job Burnout:}

The study (Tahmasebi, Sobhanipour et al. 2013) examined the relationship between organizational silence and job burnout, it found that there is a positive correlation between organizational silence, with both emotional stress and loss of personal element 
The impact of Organizational silence on Job Burnout Applied study ...

Dr. Ehab Lotfy AbdElaal Abied \& Dr. Hassan Mahmoud Aly Khalil in dealing, and the absence of significant correlation between organizational silence and Professional Accomplishment.

The study (Coban and Sarikaya 2016) found no significant correlation between any dimension of organizational silence and emotional exhaustion, while it found that there is a significant positive correlation between Acquiescent silence, Defensive silence, Depersonalization, and a negative correlation between the acquiescent silence, the defensive silence, and the Reduced Professional Accomplishment.

The study of (Akin and Ulusoy 2016) aimed to analyze the relationship between organizational silence and burnout. The study concluded that there is a positive correlation between organizational silence and job burnout, and organizational silence explains about $33 \%$ of the change in Emotional Exhaustion, and $29 \%$ of the Depersonalization, and the organizational silence explains $9 \%$ of the change in the Reduced Professional Accomplishment.

(Al-Rousan and Omoush 2018) studied the relationship between organizational silence and job burnout, the study found that there is a direct relation between organizational silence and every aspect of burnout. Organizational silence explains 84.25\% of Emotional Exhaustion change, $94.4 \%$ of change in Depersonalization and $74.56 \%$ of reduced professional Accomplishment, the organizational silence explains about $91.9 \%$ of the change in job burnout. 
The impact of Organizational silence on Job Burnout Applied study ...

Dr. Ehab Lotfy AbdElaal Abied \& Dr. Hassan Mahmoud Aly Khalil

\section{The study problem:}

In order to identify the problem and its formulation, and after reviewing the previous studies, the researcher conducted an exploratory study represented in conducting a number of (10) interviews with doctors, (15) interviews with the nursing staff at Ain Shams University Hospitals, the framework of these interviews was the initial recognition of the degree of organizational silence practice and job burnout, these interviews concluded the existence of some aspects as follows:

- Doctors and nursing staff avoid making statements and ideas about hospital work environment issues.

- Presidents do not accept any suggestions for development and prefer to issue instructions without the participation of others.

- The workers are not ready to detect problems or errors in the work believing that it is difficult to change the current situation.

- The increase of the sense of psychological and physical exhaustion due to conditions related to the nature of work such as the increase of the number of working hours and problems of dealing with patients and those accompanying them.

- Weakness of achievement due to the lack of potentials and job resources available within the hospital environment.

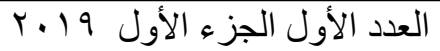

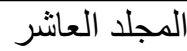


The impact of Organizational silence on Job Burnout Applied study ...

Dr. Ehab Lotfy AbdElaal Abied \& Dr. Hassan Mahmoud Aly Khalil

According to the above, the researcher can formulate the research problem in the following questions:

- Does the level of organizational silence differ between doctors and nurses in the hospitals in question?

- Does the job burnout differ between doctors and nurses in the hospitals in question?

- Does the level of organizational silence affect the job burnout at the hospitals in question?

\section{Objectives of the study:}

The aim of this study is to achieve a main objective of determining the effect of organizational silence degree on the job burnout in the society featured. To achieve this objective, a set of sub-goals could be formulated as follows:

- Identifying the difference in the level of organizational silence between doctors and nurses in the hospitals under study.

- Determining the difference in the degree of job burnout between doctors and nurses in the hospitals under study.

- Determining the effect of organizational silence level on job burnout.

- In light of the results of the study, the researcher presents a set of suggestions that may benefit the hospitals under study in reducing the level of organizational silence.

العدد الأول الجزء الأول 19 بـ

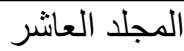


The impact of Organizational silence on Job Burnout Applied study ...

Dr. Ehab Lotfy AbdElaal Abied \& Dr. Hassan Mahmoud Aly Khalil

\section{The study hypotheses:}

In the light of the research problem and objectives, this study aims to verify the validity of a set of hypotheses which could be formulated as follows:

1- There is no significant difference between the doctors and nursing staff regarding the level of organizational silence in the hospitals under study.

2- There is no significant difference between the doctors and nurses regarding the degree of job burnout in the hospitals under study.

3- There is no significant effect for the dimensions of organizational silence on Job Burnout in the hospitals under study. The following sub-assumptions are derived from this hypothesis:

3/1 There is no significant effect for organizational silence on emotional exhaustion.

$3 / 2$ There is no significant effect for organizational silence on depersonalization.

$3 / 3$ There is no significant effect for organizational silence on reduced professional accomplishment.

\section{The importance of the study:}

The academic and practical importance of the study can be noted as follows:

العدد الأول الجزء الأول 19

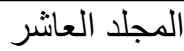


The impact of Organizational silence on Job Burnout Applied study ...

Dr. Ehab Lotfy AbdElaal Abied \& Dr. Hassan Mahmoud Aly Khalil

\section{The academic importance:}

The study contributes to the development of academic literature regarding the relationship between organizational silence and job burnout, especially as it is the first study in Egypt - to the knowledge of researchers - which deals with the phenomenon of organizational silence on doctors and nursing staff at Ain Shams University hospitals, and measuring the level of this silence and its relation to the job burnout.

\section{Practical importance:}

The study seeks to provide data and information to decision-makers about the degree of organizational burnout and its relation to organizational silence, which helps them to develop policies that will reduce job burnout, and the positive dimensions of organizational silence, and correcting the negative dimensions of organizational silence, which enables the organization to raise the performance and morale of workers, and gives them the opportunity for creativity and self-development.

\section{Method of study:}

In this section, the researcher deals with: the society and the sample of the study, the method of data collection, the tool used to collect data of the applied study, and then the statistical methods used to analyze the study data, as follows:

\subsection{Study population and Sample:}

The study population consists of all doctors and nursing

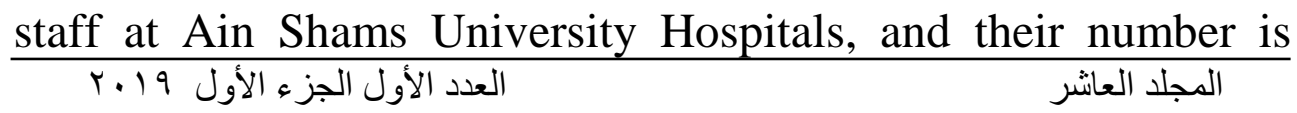


The impact of Organizational silence on Job Burnout Applied study ...

Dr. Ehab Lotfy AbdElaal Abied \& Dr. Hassan Mahmoud Aly Khalil 4618 individuals, the sample size was determined at $95 \%$ confidence level, a common level in business management research, within a standard error of 5\%, which is also an acceptable limit in business researches, the sample size was based on Idris equation $(2016)^{(1)}$, the study sample was estimated by (355) individuals, which were randomly withdrawn from the hospitals under study, and after collecting the data and examining the forms, it was found that the number of valid forms that were entered for the analysis amounted to 342 form by about $96.34 \%$ of the total number of sample which is sufficient and representative percentage, Table (1) shows the distribution of the research community size in Ain Shams University hospitals and the distribution of the sample and the number and percentage of the correct responses in each company.

${ }^{(1)}$ Idris equation:

$$
n=\frac{N\left(Z^{2} S^{2}\right)}{N e^{2}+Z^{2} e^{2}}
$$

Where $\mathrm{N}$ refers to the sample size, $\mathrm{Z}$ is the standard degree corresponding to the $95 \%$ confidence level which is $1.96, \mathrm{~S}^{2}$ is the standard deviation of 0.5 , and $E$ is the permissible error rate, spread on both ends of the distribution by an equal amount of $5 \%$, and $\mathrm{N}$ is the size of the community.

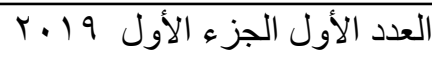

المجلد العاشر 
The impact of Organizational silence on Job Burnout Applied study ...

Dr. Ehab Lotfy AbdElaal Abied \& Dr. Hassan Mahmoud Aly Khalil

\section{Table (1)}

The size of the research population in Ain Shams University Hospitals The distribution of the sample and the number and percentage of the correct responses in each hospital

\begin{tabular}{|c|c|c|c|c|c|c|c|c|c|c|c|c|}
\hline \multirow[t]{2}{*}{\begin{tabular}{|l|} 
No. \\
\end{tabular}} & \multirow[t]{2}{*}{ Hospital Name } & \multicolumn{3}{|c|}{ Community } & \multicolumn{3}{|c|}{ The Ratio to total society } & \multicolumn{3}{|c|}{ Received surveys } & \multicolumn{2}{|c|}{$\begin{array}{l}\text { Percentage of correct } \\
\text { responses }\end{array}$} \\
\hline & & Doctors & $\begin{array}{c}\text { Nursing } \\
\text { staff }\end{array}$ & Total & Doctors & $\begin{array}{c}\text { Nursing } \\
\text { staff }\end{array}$ & Total & Doctors & $\begin{array}{c}\text { Nursing } \\
\text { staff }\end{array}$ & Total & $\begin{array}{c}\text { Doctors } \\
\%\end{array}$ & Nursing staff $\%$ \\
\hline 1 & $\begin{array}{c}\text { Ain Shams Specialized } \\
\text { Hospital }\end{array}$ & 283 & 1244 & 1527 & 39 & 78 & 117 & 38 & 77 & 115 & 97.20 & 98.35 \\
\hline 2 & Ain Shams univesisty & 615 & 701 & 1316 & 34 & 67 & 101 & 33 & 65 & 98 & 97.94 & 96.34 \\
\hline 3 & Demerdash & 352 & 502 & 854 & 22 & 44 & 66 & 21 & 43 & 64 & 96.05 & 98.21 \\
\hline 4 & $\begin{array}{c}\text { Obstetrics and } \\
\text { gynecology }\end{array}$ & 156 & 339 & \begin{tabular}{|c|}
495 \\
\end{tabular} & 13 & 25 & 38 & 11 & 23 & 34 & 86.80 & 90.63 \\
\hline 5 & Children & 132 & 294 & 426 & 11 & 22 & 33 & 10 & 21 & 31 & 91.69 & 96.15 \\
\hline & Total & 1538 & 3080 & \begin{tabular}{|l|}
4618 \\
\end{tabular} & 118 & 237 & 355 & 113 & 229 & 342 & 95.58 & 96.72 \\
\hline
\end{tabular}

Source: Ain Shams University Hospitals, Information Center, January 2018.

\subsection{Field data collection tool:}

To implement the study and in order to achieve its objectives and to prove the validity of its hypotheses, two methods were adopted:

- The Desk study method: It targeted the acquaintance of information, which enables the researcher to prepare the theoretical framework and the concepts, and to identify the results of previous studies in the field of the research, and the researcher relied on books and researches that dealt with the subject of the study as available.

- Field study method: which began by conducting a survey to identify the manifestations of the problem, and to formulate the problem of study, and then preparing a survey list to العدد الأول الجزء الأول 19 19. 
The impact of Organizational silence on Job Burnout Applied study ...

Dr. Ehab Lotfy AbdElaal Abied \& Dr. Hassan Mahmoud Aly Khalil

gather preliminary data from the study community, and to test this list and distribute and compile it in preparation to conduct the appropriate analysis.

\subsection{Field data collection tool:}

The study was based on the primary data collected from the items of the study community. The survey list was designed and used according to the standards of the study variables most commonly used in the previous studies, as follows:

Part 1: The Dimensions of Organizational Silence: It is the Independent Variable of the Study, the researcher relied on (Dyne, Ang et al. 2003) scale to measure this variable, which consisted of four dimensions, only three dimensions were studied namely, the Acquiescent Silence, Defensive Silence, Prosocial Silence. The scale consists of (15) statements. And it has been extensively developed in a number of other studies, including (Elçi, Erdilek et al. 2014) (Acaray and Akturan 2015) (Brinsfield 2009).

Part II: The dimensions of job burnout: It is the variable following the study, which consisted of several dimensions: Emotional Exhaustion, Depersonalization and Reduced Professional Accomplishment. The researcher used in the measurement of this variable the scale Maslash \& Jachson, 1981, which consists of (15) statements. And it is one of the most widely used standards, which has been relied upon in many

العدد الأول الجزء الأول 9 1.ب

المجلد العاشر 
The impact of Organizational silence on Job Burnout Applied study ...

Dr. Ehab Lotfy AbdElaal Abied \& Dr. Hassan Mahmoud Aly Khalil previous studies such as (Peltzer, Mashego et al. 2003) (Brinsfield 2009) (Tahmasebi, Sobhanipour et al. 2013).

Table (2) shows the study variables and the statement numbers in the survey list used.

\section{Table (2)}

Study variables and statement numbers in the survey list Statement numbers

\begin{tabular}{|c|c|c|}
\hline Part & Variable & No. of Statements \\
\hline \multirow{4}{*}{ One } & Organizational Silence & $1-15$ \\
\cline { 2 - 3 } & Acquiescent Silence & $1-6$ \\
\cline { 2 - 3 } & Defensive Silence & $7-11$ \\
\cline { 2 - 3 } & Prosocial Silence & $12-15$ \\
\hline \multirow{4}{*}{ Two } & Job Burnout & $1-15$ \\
\cline { 2 - 3 } & Emotional Exhaustion & $1-5$ \\
\cline { 2 - 3 } & Depersonalization & $6-10$ \\
\cline { 2 - 3 } & Reduced Professional & $11-15$ \\
\hline
\end{tabular}

Source: Prepared by the researcher.

All the expressions of the variables (independent and dependent) were put on the five-point Likert scale (1-5), where (1) means not at all agreeable, (5) means strongly agreeable.

\section{Reliability and Validity of the scale:}

Despite the Reliability and validity of the scale of organizational silence, as well as the scale of job burnout, but the researcher carried out the test of reliability and validity of the list, and the results are as shown in Table (3). 
The impact of Organizational silence on Job Burnout Applied study ...

Dr. Ehab Lotfy AbdElaal Abied \& Dr. Hassan Mahmoud Aly Khalil

\section{Table (3)}

\section{Reliability and Validity of the survey list}

\begin{tabular}{lcc}
\hline \multicolumn{1}{c}{ Variables } & $\begin{array}{c}\text { Validity } \\
\text { coefficient }\end{array}$ & Reliability coefficient \\
\hline Organizational Silence & & \\
Acquiescent Silence & $0.916^{* *}$ & $0.974^{* *}$ \\
Defensive Silence & $0.948^{* *}$ & $0.928^{* *}$ \\
Prosocial Silence & $0.851^{* *}$ & $0.844^{* *}$ \\
Job Burnout & & \\
Emotional Exhaustion & $0.942^{* *}$ & $0.840^{* *}$ \\
Depersonalization & $0.976^{* *}$ & $0.869^{* *}$ \\
Reduced Professional & $0.937^{* *}$ & $0.896^{* *}$ \\
Accomplishment & & \\
\hline Source: Statisti & & \\
\hline
\end{tabular}

Source: Statistical analysis results.

By reviewing table (3), it is clear that the values of Reliability and Validity coefficients are acceptable for all elements. The survey list included two main axes, each containing a set of elements. The reliability coefficient ranged between 0.840 for Emotional Exhaustion element from the second axis Job Burnout, and (0.974) for the element Acquiescent Silence from the first axis Organizational Silence. The values of the Validity coefficient range from 0.851 for Prosocial Silence and 0.976 for Depersonalization.

Thus it can be said that they are coefficients of good significance for research purposes and are reliable in generalizing the results.

العدد الأول الجزء الأول 9 1.r

المجلد العاشر 
The impact of Organizational silence on Job Burnout Applied study ...

Dr. Ehab Lotfy AbdElaal Abied \& Dr. Hassan Mahmoud Aly Khalil

\section{4 Statistical Methods used in Data Analysis:}

In light of the study hypotheses and its objectives, and according to the nature of the field collected data, the researcher adopted the following statistical methods:

- T test method, to detect the differences between the views of the two categories of the study regarding organizational silence, and job burnout.

- Correlation analysis, to find out the size and direction of the interrelationships between the different variables of the study.

- Regression analysis, to detect the size and direction of the effect of independent variables on dependent variables.

In addition, the Alpha coefficient is used to calculate the reliability of the scale, the arithmetic mean, and the standard deviation.

\section{Analysis :}

\section{A - Regarding the existence of a significant difference between the doctors and nursing staff about the level of organizational silence in the hospitals under study.}

The following table shows the results of the statistical analysis as follows:

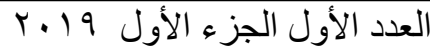

المجلد العانشر 
The impact of Organizational silence on Job Burnout Applied study ...

Dr. Ehab Lotfy AbdElaal Abied \& Dr. Hassan Mahmoud Aly Khalil

\section{Table (4)}

The results of the descriptive statistics and test $(T)$ between doctors and nursing staff on the dimensions of organizational silence

\begin{tabular}{|c|c|c|c|c|c|c|}
\hline \multirow{2}{*}{$\begin{array}{c}\text { Organizational } \\
\text { Silence Variables }\end{array}$} & \multicolumn{2}{|c|}{ Doctors } & \multicolumn{2}{|c|}{ Nursing staff } & \multicolumn{2}{|c|}{$\begin{array}{c}\text { (T) Test for } \\
\text { Equality of } \\
\text { Means }\end{array}$} \\
\cline { 2 - 7 } & Mean & $\begin{array}{c}\text { Std. } \\
\text { Error }\end{array}$ & Mean & $\begin{array}{c}\text { Std. } \\
\text { Error }\end{array}$ & T & Sig. \\
\hline $\begin{array}{c}\text { Acquiescent } \\
\text { Silence }\end{array}$ & 3.531 & 0.103 & 3.916 & 0.074 & 3.029 & 0.00 \\
\hline Defensive Silence & 3.458 & 0.134 & 3.871 & 0.072 & 2.714 & 0.00 \\
\hline Prosocial Silence & 3.821 & 0.104 & 3.606 & 0.081 & 2.632 & 0.00 \\
\hline $\begin{array}{c}\text { Organizational } \\
\text { Silence (Total) }\end{array}$ & 3.394 & 0.097 & 3.691 & 0.067 & 2.502 & 0.00 \\
\hline
\end{tabular}

Ref: Results of Statistical Analysis.

The previous table shows the following:

- The arithmetic mean of organizational silence, whether in aggregate or sub-dimensions level, was in favor of the nursing staff, where the statistical analysis showed that the arithmetic mean of the organizational silence (total) reached (3.691) for nursing staff. The analysis also showed that the arithmetic mean at the sub-dimension level ranged from $(3,821)$ maximum, (3.458) minimum for doctors, compared to (3.916) maximum, (3.606) minimum for nursing stuff.

- Statistical analysis also revealed the Materiality difference of the organizational silence dimensions for both doctors and

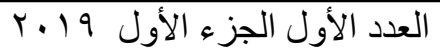

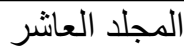


The impact of Organizational silence on Job Burnout Applied study ...

Dr. Ehab Lotfy AbdElaal Abied \& Dr. Hassan Mahmoud Aly Khalil

nursing staff, where the descending order - according to the arithmetic mean - of doctors was as follows:

1. Prosocial Silence. 2. Acquiescent Silence. 3.Defensive Silence.

While the order for nursing staff was as follows:

1. Acquiescent Silence. 2. Defensive Silence. 3. Prosocial Silence.

- It was statistically proven by using T-test that there is a significant difference between the doctors and nursing staff about the dimensions of organizational silence at a significance level of $(1 \%)$ on the total and sub-dimensions level.

Thus, it is clear that there is a significant difference between the doctors and nurses regarding the level of organizational silence in the hospitals under study, which proves the invalidity of the first hypothesis of the study.

\section{B - Regarding the existence of a significant difference between both the doctors and the nursing staff about the job burnout in the hospitals under study.}

The following table shows the results of the statistical analysis as follows:

العدد الأول الجزء الأول 9 1.r

المجلد العانشر 
The impact of Organizational silence on Job Burnout Applied study ...

Dr. Ehab Lotfy AbdElaal Abied \& Dr. Hassan Mahmoud Aly Khalil

\section{Table (5)}

Results of the descriptive statistics and test ( $T$ ) between doctors and nursing staff about the dimensions of job burnout

\begin{tabular}{|c|c|c|c|c|c|c|}
\hline \multirow{2}{*}{$\begin{array}{c}\text { Job Burnout } \\
\text { Variables }\end{array}$} & \multicolumn{2}{|c|}{ Doctors } & \multicolumn{3}{c|}{ Nursing staff } & \multicolumn{2}{c|}{$\begin{array}{c}\text { (T) Test for } \\
\text { Equality of } \\
\text { Means }\end{array}$} \\
\cline { 2 - 7 } & Mean & $\begin{array}{c}\text { Std. } \\
\text { Error }\end{array}$ & Mean & $\begin{array}{c}\text { Std. } \\
\text { Error }\end{array}$ & T & Sig. \\
\hline $\begin{array}{c}\text { Emotional } \\
\text { Exhaustion }\end{array}$ & 3.936 & 0.096 & 3.969 & 0.069 & 2.279 & 0.00 \\
\hline Depersonalization & 3.511 & 0.101 & 4.174 & 0.087 & 4.164 & 0.00 \\
\hline $\begin{array}{c}\text { Reduced } \\
\text { Professional } \\
\text { Accomplishment }\end{array}$ & 3.821 & 0.103 & 3.606 & 0.081 & 2.632 & 0.00 \\
\hline Job Burnout (Total) & 3.723 & 0.094 & 4.065 & 0.071 & 2.402 & 0.02 \\
\hline
\end{tabular}

Ref: Results of Statistical Analysis.

The previous table shows the following:

- The arithmetic mean of job burnout, whether in aggregate or sub-dimensions level, was in favor of nursing staff. Statistical analysis showed that the arithmetic mean of job burnout (total) reached (4.065) for nursing staff. The analysis also showed that the arithmetic mean at the sub-dimensions level ranged from $(3,936)$ maximum, $(3,511)$ minimum for doctors, compared to (4.174) maximum, (3.606) minimum for nursing staff.

- Statistical analysis also showed the Materiality difference of the organizational silence dimensions for both doctors and

العدد الأول الجزء الأول 19.

المجلد العاشر 
The impact of Organizational silence on Job Burnout Applied study ...

Dr. Ehab Lotfy AbdElaal Abied \& Dr. Hassan Mahmoud Aly Khalil nurses, where the descending order - according to the arithmetic mean - of the doctors came as follows:

1. Emotional Exhaustion. 2. Reduced Professional 3. Accomplishment. 3. Depersonalization.

While the arrangement for nursing staff was as follows:

1. Depersonalization. 2. Emotional Exhaustion. 3. Reduced Professional Accomplishment.

- It was statistically proven by using (T) test that there is a significant difference between doctors and nursing staff on the dimensions of the job burnout, at a significance level $(1 \%)$ on the total and sub-dimensions levels.

Thus, it is clear that there is a significant difference between the doctors and nurses regarding the level of organizational silence in the hospitals under study, which proves the invalidity of the first hypothesis of the study.

\section{(C) The effect of organizational silence dimensions on job burnout.}

The correlation coefficients among study variables are presented in Table 6 . The organizational silence have a significant positive correlation with all dimensions of Job Burnout. Moreover, The regression model is conducted three times according to each dimension of organizational Silence, which are illustrated in table 7.

The first regression model determines the influence of

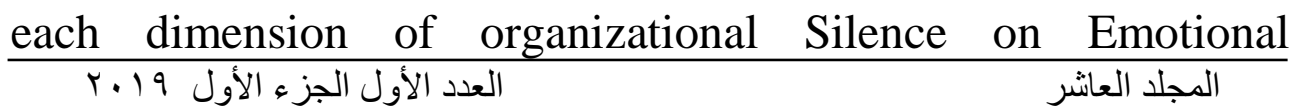


The impact of Organizational silence on Job Burnout Applied study ...

Dr. Ehab Lotfy AbdElaal Abied \& Dr. Hassan Mahmoud Aly Khalil

exhaustion. The fitted model was significant according to the value of $F$ test $(F=530.963, \rho<0.001)$ and the interpreted power of the model was $75.4 \%$ as represented by $\mathrm{R}^{2}$. The results of this model indicate that Defensive Silence and Prosocial Silence have a significantly positive effect on motional exhaustion.

The second regression model, which tests the impact of organizational silence dimensions on Depersonalization is also significant $(F=504.654, \rho<0.001)$ and the interpreted power of the model was $85.4 \%$ as represented by $\mathrm{R}^{2}$. It shows that Acquiescent Silence, Defensive Silence and Prosocial Silence are the significant factors affecting depersonalization.

The third regression model, which tests the impact of organizational silence dimensions on Reduced Professional Accomplishment is also significant $(F=218.687, \rho<0.001)$ and the interpreted power of the model was $55.8 \%$ as represented by $\mathrm{R}^{2}$. It shows that Acquiescent Silence and Prosocial Silence are the significant factors affecting reduced professional accomplishment.

العدد الأول الجزء الأول 9 1.r

المجلد العانشر 
The impact of Organizational silence on Job Burnout Applied study ...

Dr. Ehab Lotfy AbdElaal Abied \& Dr. Hassan Mahmoud Aly Khalil

\section{Table (6)}

Descriptive statistics: means, standard deviations, and correlation matrix of study variables

\begin{tabular}{|c|c|c|c|c|c|c|}
\hline Variables & $\begin{array}{c}\text { Acquiescent } \\
\text { Silence }\end{array}$ & $\begin{array}{c}\text { Defensive } \\
\text { Silence }\end{array}$ & $\begin{array}{l}\text { Prosocial } \\
\text { Silence }\end{array}$ & $\begin{array}{l}\text { Emotional } \\
\text { Exhaustion }\end{array}$ & $\begin{array}{l}\text { Deperson- } \\
\text { alization }\end{array}$ & $\begin{array}{c}\text { Reduced } \\
\text { Professional } \\
\text { Accomplishment }\end{array}$ \\
\hline Acquiescent Silence & & & & & & \\
\hline Defensive Silence & $0.874^{* *}$ & & & & & \\
\hline Prosocial Silence & $0.754^{* *}$ & $0.745^{* *}$ & & & & \\
\hline Emotional & $0.738^{* *}$ & $0.777^{* *}$ & $0.838^{* *}$ & & & \\
\hline Exhaustion & & & & & & \\
\hline Depersonalization & $0.904^{* *}$ & $0.807^{* *}$ & $0.586^{* *}$ & $0.618^{* *}$ & & \\
\hline $\begin{array}{l}\text { Reduced } \\
\text { Professional } \\
\text { Accomplishment }\end{array}$ & $0.671^{*}$ & $0.634^{* *}$ & $0.718^{* *}$ & $0.749^{* * *}$ & $0.607^{* *}$ & \\
\hline
\end{tabular}

Note. ${ }^{*} \mathrm{p}<0.05 ;{ }^{* *} \mathrm{p}<0.01$.

Table (7)

The test of the effects of Organizational Silence on Dimensions of Job Burnout

\begin{tabular}{lccc}
\hline \multicolumn{1}{c}{ Variables } & $\begin{array}{c}\text { Emotional } \\
\text { Exhaustion }\end{array}$ & $\begin{array}{c}\text { Depersonalizati } \\
\text { on }\end{array}$ & $\begin{array}{c}\text { Reduced } \\
\text { Professional } \\
\text { Accomplishment }\end{array}$ \\
\cline { 2 - 4 } & $\beta^{\text {(sig.) }}$ & $\beta^{\text {(sig.) }}$ & $\beta^{\text {(sig.) }}$ \\
\hline Acquiescent Silence & -0.003 & $0.193^{* *}$ & $0.294^{* *}$ \\
Defensive Silence & $0.295^{* *}$ & $0.188^{* *}$ & 0.023 \\
Prosocial Silence & $0.509^{* *}$ & $-0.299^{* *}$ & $0.456^{* *}$ \\
$\mathrm{R}^{2}$ & 0.754 & 0.845 & 0.555 \\
$\mathrm{~F}^{\text {(sig.) }}$ & $530.963^{* *}$ & $625.606^{* *}$ & $215.723^{* *}$ \\
\hline $\mathrm{N}^{*}$ & & & \\
\hline
\end{tabular}

Note. ${ }^{*} \mathrm{p}<0.05 ;{ }^{* *} \mathrm{p}<0.01$.

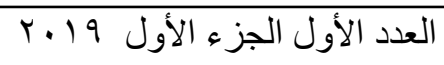


The impact of Organizational silence on Job Burnout Applied study ...

Dr. Ehab Lotfy AbdElaal Abied \& Dr. Hassan Mahmoud Aly Khalil

\section{Conclusions}

The aim of this study was to investigate the extent to which organizational silence affects job burnout of both doctors and nurses. And through the theoretical rooting of the study variables and the review of the results of previous studies, it became clear that the dimensions of organizational silence can be identified in: Acquiescent Silence, Defensive Silence and Prosocial Silence. It became clear also that the dimensions of job burnout that have almost reached an agreement are: Emotional Exhaustion, Depersonalization and Reduced Professional Accomplishment. It was possible to formulate a set of study hypotheses to show the extent of differences between doctors and nurses on the dimensions of organizational silence and job burnout in Ain Shams University hospitals and the effect of organizational silence (independent variable) on job burnout (dependent variable). The results of the study showed the following:

1-There is a significant difference between doctors and nursing staff on the level of all organizational silence dimensions at a significance level of 5\%. And the most significant organizational silence dimension for physicians is Prosocial Silence, The researcher believes that this may be due to doctors trying to make a decision to block information or opinions that may cause harm to others or result in damage at

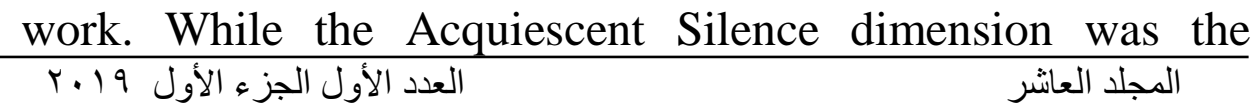


The impact of Organizational silence on Job Burnout Applied study ...

Dr. Ehab Lotfy AbdElaal Abied \& Dr. Hassan Mahmoud Aly Khalil

highest for nursing staff, and the researcher suggests that this may be due to the surrender or subordination of nursing staff to the status quo and that they are convinced of the difficulty of change.

2- There is a significant difference between doctors and nursing staff at the level of all dimensions of job burnout at a significance level of $5 \%$. The highest dimension for job burnout for doctors is Emotional Exhaustion and the researcher believes that this may be due to the continuous increase in workloads within the hospitals under study, While Depersonalization dimension was the most for nursing staff, the researcher suggests that this may be due to the high pressure of work and the sense of nursing staff that they are treated as things and not as human beings.

3-The dimensions of organizational silence: Acquiescent Silence, Defensive Silence and Prosocial Silence, have a significant and positive effect on Emotional Exhaustion at a significance level of $1 \%$, which accounts for $75.4 \%$ of the volume of change. which means that there is about $24.6 \%$ (which is the unexplained part), that requires researchers to add a set of other variables - in addition to the organizational silence - to explain this part, This finding is consistent with the study of (Tahmasebi, Sobhanipour et al. 2013) (Coban and Sarikaya 2016) (Al-Rousan and Omoush 2018).

العدد الأول الجزء الأول 9 1.r

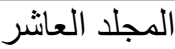


The impact of Organizational silence on Job Burnout Applied study ...

Dr. Ehab Lotfy AbdElaal Abied \& Dr. Hassan Mahmoud Aly Khalil

4- The dimensions of organizational silence: Acquiescent Silence, Defensive Silence and Prosocial Silence have a significant and positive impact on Depersonalization at a significance level of $1 \%$, accounting for $84.5 \%$ of the volume of change. which means that there is about $15.5 \%$ (which is the unexplained part), that requires the researchers to add a set of other variables - in addition to the organizational silence - to explain this part and this result agree with the study of (Tahmasebi, Sobhanipour et al. 2013) (Al-Rousan and Omoush 2018).

5-The dimensions of organizational silence: Acquiescent Silence, Defensive Silence and Prosocial Silence have a significant and positive impact on Reduced Professional Accomplishment at a significance level of $1 \%$, accounting for $55.5 \%$ of the volume of change. Which means that there is about $44.5 \%$ (which is the unexplained part), which requires researchers to add a set of other variables - in addition to the organizational silence - to explain this part and this result agree with the study of (Al-Rousan and Omoush 2018).

\section{Recommendations}

In light of the results of the applied study, the researcher suggests some recommendations that may contribute to overcome the spread of the dimensions of the organizational silence for both doctors and nursing staff in Ain Shams

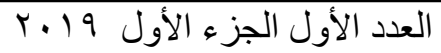

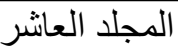


The impact of Organizational silence on Job Burnout Applied study ...

Dr. Ehab Lotfy AbdElaal Abied \& Dr. Hassan Mahmoud Aly Khalil

University hospitals, which is reflected in the various forms of burnout, as follows:

- The need for officials at Ain Shams University hospitals to adopt a culture that encourages and urges employees to talk and not to remain silent so that the administration can monitor and know the problems of work and try to solve them to prevent the aggravation.

- The need for the attention of officials at Ain Shams University hospitals to develop effective channels of communication between them and both doctors and nurses, and encourage the regular exchange of information between departments and different divisions, which ensures their participation in the problems and issues of work and reduces their silence.

- Building accountability and accounting systems, protecting the right to express opinions and preserving the rights of employees.

- Directing and encouraging employees to practice positive social silence through an encouraging regulatory environment based on an effective communication system.

- The importance of creating a supportive organizational environment to build good working relations within hospitals, which encourages the discussion of problems or issues of work in hospitals.

العدد الأول الجزء الأول 9 1.r

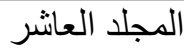


The impact of Organizational silence on Job Burnout Applied study ...

Dr. Ehab Lotfy AbdElaal Abied \& Dr. Hassan Mahmoud Aly Khalil

- Training of doctors, nurses and leaders in Ain Shams University hospitals on effective communication skills through workshops and training courses.

\section{Suggestions for future researches:}

Although the current research has contributed to the study of the effect of organizational silence on job burnout for doctors and nursing staff at Ain Shams University hospitals in an unprecedented manner in the Arab and foreign studies, however, the field is still open to continue and complete the research in this area as follows:

- Studying the impact of organizational silence on job burnout in public and private hospitals.

- Studying the impact of the centering of organizational justice on the relationship between organizational silence and job burnout in hospitals.

- Studying the effect of organizational silence on the organizational results of silence such as career absorption, organizational citizenship behaviors, turnover, organizational learning in Ain Shams University hospitals.

العدد الأول الجزء الأول 19

المجلد العاشر 
The impact of Organizational silence on Job Burnout Applied study ...

Dr. Ehab Lotfy AbdElaal Abied \& Dr. Hassan Mahmoud Aly Khalil

\section{References}

Acaray, A. and A. Akturan (2015). "The relationship between organizational citizenship behaviour and organizational silence." Procedia-Social and Behavioral Sciences 207: 472-482.

Adriaenssens, J., et al. (2015). "Determinants and prevalence of burnout in emergency nurses: a systematic review of 25 years of research." International journal of nursing studies 52(2): 649-661.

Akin, U. and T. Ulusoy (2016). "The Relationship between Organizational Silence and Burnout among Academicians: A Research on Universities in Turkey." International Journal of Higher Education 5(2): 46-58.

Al-Rousan, M. A. M. and M. M. Omoush (2018). "The Effect of Organizational Silence on Burnout: A Field Study on Workers at Jordanian Five Star Hotels." Journal of Management and Strategy 9(3).

Bagheri, G., et al. (2012). "Organizational silence (basic concepts and its development factors)." Ideal Type of Management 1(1): 47-58.

Baran, H. and C. Giderler (2017). "A study on determining the influence of organizational identification on organizational justice and organizational silence." International Journal of Asian Social Science 7(3): 242-258.

Beheshtifar, M., et al. (2012). "Destructive role of employee silence in organizational success." International Journal of Academic Research in Business and Social Sciences 2(11): 275.

Brinsfield, C. T. (2009). Employee silence: Investigation of dimensionality, development of measures, and examination of related factors, The Ohio State University.

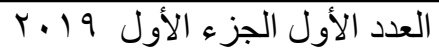

المجلد العاشر 
The impact of Organizational silence on Job Burnout Applied study ...

Dr. Ehab Lotfy AbdElaal Abied \& Dr. Hassan Mahmoud Aly Khalil

Çakıc1, A. (2008). "A research on issues, causes and perceptional results of silence at organizations." Journal of Çukurova University Institute of Social Sciences 17(1): 117-134.

Cañadas-De la Fuente, G. A., et al. (2015). "Risk factors and prevalence of burnout syndrome in the nursing profession." International journal of nursing studies 52(1): 240-249.

Carolina, D. S. (2010). Correlates of job-related burnout in nurse managers working in hospitals, Rutgers University-Graduate School-Newark.

Çınar, O., et al. (2013). "The relationship between organizational silence and organizational citizenship behavior: a survey study in the province of Erzurum, Turkey." Procedia-Social and Behavioral Sciences 99: 314-321.

Coban, H. and M. Sarikaya (2016). "A Research On The Relationship Between Organizational Silence And Burnout." European Scientific Journal, ESJ 12(10).

Day, A. L., et al. (2009). "Workplace risks and stressors as predictors of burnout: The moderating impact of job control and team efficacy." Canadian Journal of Administrative Sciences/Revue Canadienne des Sciences de l'Administration 26(1): 7-22.

Deniz, N., et al. (2013). "The relationship between employee silence and organizational commitment in a private healthcare company." Procedia-Social and Behavioral Sciences 99: 691-700.

Dyne, L. V., et al. (2003). "Conceptualizing employee silence and employee voice as multidimensional constructs." Journal of management studies 40(6): 1359-1392.

Elçi, M., et al. (2014). "The mediating role of mobbing on the relationship between organizational silence and turnover intention." ProcediaSocial and Behavioral Sciences 150: 455-464.

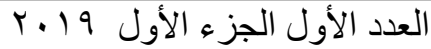

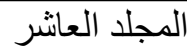


The impact of Organizational silence on Job Burnout Applied study ...

Dr. Ehab Lotfy AbdElaal Abied \& Dr. Hassan Mahmoud Aly Khalil

França, F. M. d., et al. (2012). "Burnout and labour aspects in the nursing teams at two medium-sized hospitals." Revista latino-americana de enfermagem 20(5): 961-970.

Kopelman, R. E., et al. (2008). "Douglas McGregor's theory X and Y: Toward a construct-valid measure." Journal of Managerial Issues: 255-271.

Kostiuk, D. D. (2012). Silence: The reasons why people may not communicate, University of Missouri--Columbia.

Lambert, E. G., et al. (2012). "Examining the relationship between supervisor and management trust and job burnout among correctional staff." Criminal Justice and Behavior 39(7): 938-957.

Majerníková, L. and A. Obročníková (2017). "Personality predictors and their impact on coping with burnout among students preparing for the nursing and midwifery profession." Kontakt 19(2): e93-e98.

Maruyama, A., et al. (2016). "Factors affecting burnout in female nurses who have preschool-age children." Japan Journal of Nursing Science 13(1): 123-134.

Morrison, E. W. and F. J. Milliken (2000). "Organizational silence: A barrier to change and development in a pluralistic world." Academy of Management review 25(4): 706-725.

Nikolaou, I., et al. (2011). "The role of silence on employees' attitudes "the day after" a merger." Personnel Review 40(6): 723-741.

Panahi, B., et al. (2012). "An empirical analysis on influencing factors on organizational silence and its relationship with employee's organizational commitment." Management Science Letters 2(3): 735-744.

Peltzer, K., et al. (2003). "Occupational stress and burnout among South African medical practitioners." Stress and Health: Journal of the International Society for the investigation of Stress 19(5): 275-280.

العدد الأول الجزء الأول 19

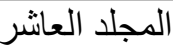


The impact of Organizational silence on Job Burnout Applied study ...

Dr. Ehab Lotfy AbdElaal Abied \& Dr. Hassan Mahmoud Aly Khalil

Pinder, C. C. and K. P. Harlos (2001). Employee silence: Quiescence and acquiescence as responses to perceived injustice. Research in personnel and human resources management, Emerald Group Publishing Limited: 331-369.

Qureshi, H. A., et al. (2015). "Burnout phenomenon in US plastic surgeons: risk factors and impact on quality of life." Plastic and reconstructive surgery 135(2): 619-626.

Sayğan, F. N. (2011). "Relationship between affective commitment and organizational silence: A conceptual discussion." International journal of social sciences and humanity studies 3(2): 219-227.

Schaufeli, W. B., et al. (2009). "Burnout: 35 years of research and practice." Career development international 14(3): 204-220.

Tahmasebi, F., et al. (2013). "Burnout; explaining the role of organizational silence and its influence (Case study: Selected executive organizations of Qom province)." Journal of Basic and Applied Scientific Research 3(8): 272-282.

Tangirala, S. and R. Ramanujam (2008). "Employee silence on critical work issues: The cross level effects of procedural justice climate." Personnel psychology 61(1): 37-68.

العدد الأول الجزء الأول 19 1.r المجلد العاشر 